\title{
Áreas de preservação permanente urbanas e parques lineares na Região Norte: conflitos na Lagoa dos Índios, Macapá - Amapá
}

\author{
José Marcelo Martins Medeiros, \\ Brenda Beserra Uliana, \\ Dayanne dos Santos Araújo*
}

\begin{abstract}
Resumo As áreas de preservação permanente têm sido ocupadas e degradadas pela expansão urbana sem planejamento nas cidades amazônicas. As áreas úmidas estão nessa categoria, e são conhecidas como "áreas de ressaca" na cidade de Macapá, capital do Amapá. Um trecho da ressaca da Lagoa dos Índios, objeto deste estudo, foi recentemente aterrado para a ampliação de uma rodovia e sofreu um Termo de Ajustamento de Conduta pelo ministério público do estado, visando a criação de um grande parque urbano. A ideia inicial do parque foi alterada com a delimitação de uma nova Área de Proteção Ambiental - APA. Esta pesquisa busca analisar os conflitos para a efetivação de um parque linear ao longo das margens da Lagoa dos Índios.
\end{abstract}

Palavras-chave: Região Norte do Brasil, parques lineares, área de preservação permanente, Lagoa dos Índios.

\section{Areas de preservación urbana permanen- te y parques lineales en la Región Norte: conflictos en Lagoa dos Índios, Macapá - Amapá}

\begin{abstract}
Resumen Las áreas de preservación permanente han sido ocupadas y degradadas por la expansión urbana sin planificación en las ciudades amazónicas. Las áreas húmedas están en esa categoría, y se conocen como "áreas de resaca" en la ciudad de Macapá. Un trecho de la resaca de la Laguna de los Indios, objeto de este estudio, fue recientemente aterrizado para la ampliación de una carretera y sufrió un Término de Ajuste de Conducta por el ministerio público, buscando la creación de un parque. La idea inicial del parque fue alterada con la delimitación de un nuevo Área de Protección Ambiental. Esta investigación busca analizar los conflictos para la efectividad de un parque lineal a lo largo de los márgenes de la laguna.
\end{abstract}

Palabras clave: Región Norte de Brasil, parques lineales, Laguna de los Indios, área de preservación permanente.
Permanent urban preservation areas and linear parks in the Northern Region: conflicts in Lagoa dos Índios, Macapá - Amapá

\begin{abstract}
The urban sprawl without planning in the Amazonian cities is degrading the areas of permanent preservation. The wetlands are in this category, also known as "ressaca" by Macapa population, the capital of Amapa state. A section of the Lagoa dos Índios wetlands, the object of this study, was recently landed for the expansion of a highway and underwent a Term of Adjustment of Conduct by the public ministry of the state, aiming at the creation of a large urban park. The delimitation of a new Area of Environmental Protection - APA distorted the initial idea of the park. This research seeks to analyze the conflicts for the implementation of a linear park along the banks of the Lagoa dos Indios.
\end{abstract}

Keywords: Northern Brazil, linear parks, Lagoa dos Indios, permanent preservation área. 

margens eram drenadas e planificadas, para o aproveitamento dos solos para a expansão urbana, assim como o plantio. Com a perda das matas ripárias, as vazões naturais foram alteradas, e as águas passaram a escoar com maior velocidade, aumentando os riscos de erosão e inundações, trazendo grandes prejuízos para os ecossistemas. No entanto, verifica-se que, sobretudo em nosso país, a temática de integração dos aspectos socioculturais e biofísicos relativos às orlas urbanas ainda é pouco abordada, mesmo nas iniciativas do poder público.

É somente a partir da metade do século XX, no entanto, que surgiram teorias, paradigmas e conceitos, ainda vagos, sobre uma relação homem-natureza que respeitava o meio ambiente. Mas é principalmente a partir da década de 80 que várias metodologias e modelagens de espaços livres, sobretudo aqueles ao longo de rios, foram estudadas e postas em prática.

Os projetos de parques lineares ao longo de cursos d'água podem ajudar na recuperação das margens que foram retificadas ou alteradas de alguma forma, e, além dos benefícios ecológicos, também trazem muitos benefícios para a recreação da população. No entanto, eles geralmente necessitam de grandes áreas verdes e investimentos, porém sua implantação é simples, sendo práticas possíveis de serem realizadas mesmo com as restrições existentes no meio urbano.

No entanto, verifica-se que, no Brasil, poucos são os projetos de recuperação de rios urbanos que têm sido criados com a abrangência dos exemplos internacionais. Existe uma grande dificuldade na implantação das propostas no contexto nacional. Na maioria das vezes, os planos são implantados apenas parcialmente, devido à falta de investimentos e de vontade política.

* José Marcelo Martins Medeiros é Arquiteto e Urbanista, Professor da Universidade Federal do Tocantins, ORCID <http://orcid. org/0000-0002-2554-8289> Brenda Beserra Uliana é Arquiteta e Urbanista, Departamento de Ciências Exatas e Tecnológicasda Universidade Federal do Amapá, ORCID <http://orcid.org/00000003-0717-1286>. Dayanne dos Santos Araújo, Engenheira Ambiental, Universidade do Estado do Amapá, <http://orcid. org/0000-0002-9798-6122>.
É grande o número de áreas de várzea situadas nas zonas urbanas e periurbanas da cidade de Macapá, capital do Amapá, conhecidas como "ressacas". Estas áreas vêm sendo ocupadas de forma acelerada e desordenada, devido à falta de planejamento urbano. Conforme Medeiros (2016), os projetos de parques lineares ao longo de cursos d'água podem ajudar na recuperação das margens que foram retificadas ou alteradas de alguma forma, e, além dos benefícios ecológicos, também trazem muitos benefícios para a recreação da população.

A criação de uma legislação ambiental no contexto brasileiro, como a criação das Áreas de Preservação Permanente e seu aproveitamento no estudo de um futuro projeto para a Lagoa dos índios, na zona oeste de Macapá, foi inspirada em muitos conceitos advindos da metodologia de implantação de parques lineares. A característica principal dos parques lineares, segundo Ahern (1995), é a sua linearidade e que a rede formada pelos seus caminhos deve criar vínculos e conexões espaciais em várias 
Figura 1: Emerald Necklace, em Boston. Fonte: Foto dos autores, março de 2010. escalas. Também são espaços predominantemente multifuncionais e que os objetivos devem levar em conta as questões ambientais e econômicas.

"Os parques lineares estão se tornando ferramentas importantes para o planejamento de espaços livres urbanos e criação de políticas públicas voltadas à busca de uma melhor qualidade de vida para a população". (MEDEIROS, 2016, p.68)

No momento contemporâneo, existe no planejamento, a ativa prerrogativa de recuperação e preservação ambiental com enfoque nos recursos hídricos e nos corredores verdes, demonstrando que há uma contínua preocupação e inserção das questões ambientais na criação de espaços livres mais equilibrados.

Morfologicamente, portanto, os parques lineares caracterizam-se pela pequena dimensão no sentido da largura em relação ao seu comprimento. Segundo Macedo (2012), a finalidade de um parque linear está sempre centrada no aproveitamento formal e conservação de um corpo d'água ou de remanescentes de matas nativas, sendo que esses elementos sempre balizam morfologicamente o logradouro.

\section{Abordagem conceitual de parques lineares}

Em termos teóricos, há uma clara tendência à utilização da Ecologia da Paisagem em projetos de parques lineares. Do ponto de vista histórico, há clara proximidade de criação de caminhos ao longo de rios, propostas já utilizadas empiricamente por Frederick Law Olmsted. Este projetista introduziu o conceito de parksways em 1865, conceituando-os como caminhos que ligam parques e espaços abertos entre si e com suas vizinhanças. Seus ideais visionários foram empregados com sucesso no final dos anos 1860 no Sistema de Parques para Boston, que ficou conhecido como "Boston's Emerald Necklace", o "Colar de Esmeralda de Boston", de aproximadamente 7,2 km de extensão (Figura 1).

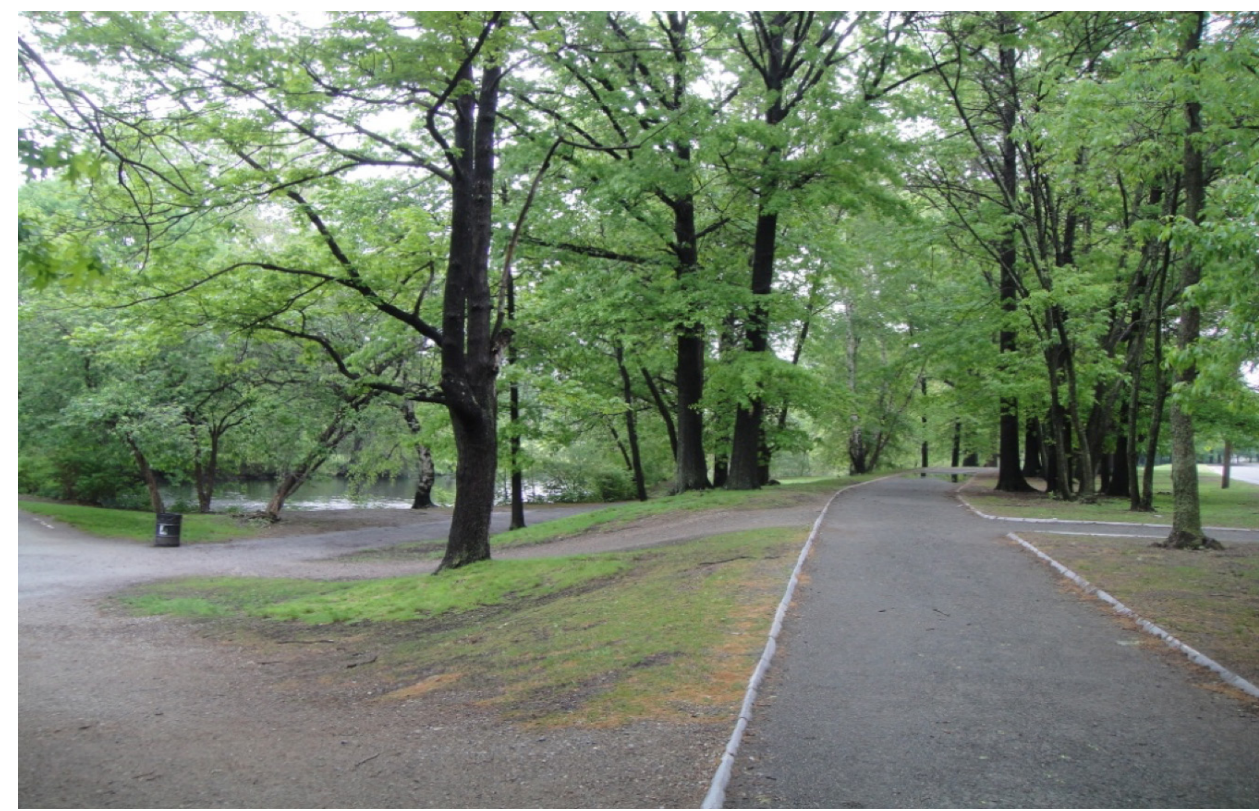


Olmsted enfatizava preocupações sociais e estéticas na maioria dos seus trabalhos porque eram as necessidades mais importantes do seu tempo. No entanto, para o desenho do sistema de parques de Boston, ele também endereçou problemas de drenagem e qualidade da água. O "Emerald Necklace" tornou-se um dos projetos mais famosos de Olmsted, na qual as soluções ambientais e as necessidades de lazer e descanso da população foram relacionadas em uma solução única (figura 2).

Como referencial para se entender as principais diretrizes para o planejamento de parques lineares, tomaremos como referência os estudos da Ecologia da Paisagem, dentre os quais, principalmente conceitos como de "corredor" (Forman e Godron, 1986; Forman, 1995) e dos "corredores verdes" (Smith e Hellmund, 1993; Ahern, 1995; Fábos, 1995, 2004).

Na década de 90, Forman $(1983,1995)$ ilustrou as principais funções ecológicas desempenhadas pelos corredores: habitat, conectividade, filtro ou barreira, fonte e depósito. Os corredores, para esse autor, também são importantes na proteção da biodiversidade, no gerenciamento de recursos hídricos, como melhora da qualidade da água e controle de cheias, no aumento da produtividade agroflorestal, na recreação, na coesão cultural e de comunidades e na diversificação de rotas para espécies isoladas em reservas.

Conforme Giordano (2000), na literatura internacional, o conceito de parques lineares está muito ligado ao conceito de corredores verdes, ou seja, um termo que está imbuído de conceitos da Ecologia da Paisagem. No livro Greenways: a guide to planning, design, and development (1993), Flink e Searns (1993) conceituam corredores verdes como espaços livres lineares que preservam e restauram a natureza em cidades, subúrbios e áreas rurais, provando ser o conceito mais inovador de proteção do solo nesta década.

Para que os corredores verdes cumpram melhor suas funções ecológicas, devem, preferencialmente, acompanhar os cursos d'água, pois assim auxiliarão no trânsito de espécies silvestres, assim como no equilíbrio do ciclo hidrológico, "contribuindo inclusive para o controle da permeabilidade da cidade de forma fracionada e adequada" (BROCANELI, 2007, p.225).

Várias metodologias têm sido desenvolvidas para conceber corredores verdes eficazes. Sensoriamento remoto, Sistema de Informação Geográfica (SIG) e quantificação da fauna, flora, ambiente físico e perturbação antrópica são amplamente utilizados em análises baseadas em realizações de mapas temáticos. As pesquisas envolvendo a análise ambiental de uma área de estudo, em que são identificados vários condicionantes e realizados uma sobreposição de informações, ficaram conhecidos como "Métodos de Apropriação da Paisagem" (Landscape Suitability Approach) e têm forte tradição com planejamento ambiental (McHarg, 1969; Steinitz, Parker e Jordan,1976; Smith e Hellmund, 1993; Searns, 1995; Giordano e Riedel, 2006; M'Ikiugu, Kinoshita e Tashiro, 2012, entre outros).

Um dos primeiros estudiosos a conceituar os corredores verdes foi Ahern (1995), na metade da década de 90. Ele faz uma contribuição importante, na medida em que suas definições se adequam ao planejamento de parques lineares urbanos. A característica principal desses espaços, segundo Ahern, é a sua linearidade e que a 
rede formada pelos seus caminhos deve criar vínculos e conexões espaciais em várias escalas. Também são espaços predominantemente multifuncionais e que os objetivos devem levar em conta as questões ambientais e econômicas.

Morfologicamente, portanto, os parques lineares caracterizam-se pela pequena dimensão no sentido da largura em relação ao seu comprimento. Segundo Macedo (2012), a finalidade de um parque linear está sempre centrada no aproveitamento formal e conservação de um corpo d'água ou de remanescentes de matas nativas, sendo que esses elementos sempre balizam morfologicamente o logradouro. Sua configuração espacial estende-se pelo equivalente a muitas quadras e corta áreas significativas do tecido urbano. Ainda segundo esse autor, eles tornaram-se comuns recentemente no Brasil, levando ao surgimento de inúmeros espaços livres públicos, ou ao menos à criação de estoques de terras para a criação de futuros parques. Conforme Macedo (2012):

Os parques lineares, típicos dos anos 2000, caracterizam-se pelo apelo conservacionista dos seus princípios geradores, que condicionam a sua existência, a princípio, à proteção de corpos d'água, em especial pequenos rios e riachos. (MACEDO, 2012, p. 164)

Existem várias metodologias de planejamento de parques lineares, que dependem de diferentes fatores. Segundo Flink e Searns (1993), existem dois fatores-chave para o início de qualquer plano: uma completa investigação da área onde será implantado o parque linear, bem como o futuro envolvimento com o público. Eles sugerem um processo de planejamento de parques lineares composto por três fases principais: inventário e análise (levantamento dos recursos naturais e culturais do corredor), preparação do plano conceitual (definição de metas, objetivos e programa de ações recomendadas) e preparação do plano final (documento especificando e alocando todas as modificações propostas para a área, com detalhada estimativa de custos). Segundo Giordano e Riedel (2006):

As informações reunidas na fase de inventário devem ser reorganizadas conforme a técnica de sobreposição de mapas, proposta por McHarg, subsidiando, assim, a segunda fase do processo de planejamento, a de preparação do plano conceitual. Nessa fase, são definidos os objetivos. (GIORDANO E RIEDEL, 2006, p.141)

Giordano e Riedel (2006) entram no detalhamento do planejamento dos parques lineares, detalhando as várias metodologias e as várias etapas desde o plano conceitual até a concepção do projeto executivo.

Os planos conceituais normalmente são apresentados de forma gráfica ou dissertativa e devem apresentar alternativas de desenvolvimento, considerando as vantagens e desvantagens de cada uma. Na fase de preparação do plano final, uma das formas de desenvolvimento para o parque linear deve ser escolhida e apresentada, contendo sua localização exata, medidas de proteção e conservação dos recursos naturais, forma de acesso e infraestruturas disponíveis, especificações de manejo, estimativa de custos de implantação e estratégias de desenvolvimento. (GIORDANO E RIEDEL, 2006, p.141) 
Conclui-se que o desenvolvimento tecnológico e a utilização de técnicas computacionais avançadas em constante evolução revelam-se de grande interesse para a investigação e a elaboração de estudos de análise da paisagem. O refinamento e a continuação de pesquisas sobre esse tema podem ajudar projetistas e entidades governamentais locais a criar espaços ambientalmente equilibrados em suas comunidades.

\section{Parques lineares da Região Norte}

Segundo Macedo (2012), as capitais da região Norte iniciam o século XXI aproveitando paisagisticamente os trechos de suas extensas orlas fluviais, que eram antes ocupadas por casarios e instalações portuárias, de acesso bastante difícil ao cidadão. A implantação de parques lineares ainda é pouco difundida no Brasil, os autores através de uma pesquisa de iniciação científica da Universidade Federal do Amapá, iniciaram um "glossário de parques lineares" das diversas regiões do Brasil, em 2017.

No estado do Acre, o Parque da Maternidade nas margens do igarapé da Maternidade (2002) cruza toda a cidade de Rio Branco, é um projeto de coordenação das arquitetas Alejandra Devecchi e Eliane Guedes. O parque foi criado para evitar enchentes, conservar as águas e vegetação por meio de um corredor verde para proporcionar lazer e qualidade social do espaço público da cidade (quadro 1).

Após a requalificação paisagística com áreas verdes, calçadas e ciclovias, o Parque da Maternidade se tornou um lugar de convivência, atração de pessoas e valorizou o entorno, sendo um destino também de compras e lazer (MEDEIROS, 2016). O projeto do parque possui caráter de corredor ecológico, tendo que promover um trabalho de remoção de muitas famílias que lançavam dejetos domésticos no rio.

Na cidade de Manaus, em 2007, a Secretaria de Meio Ambiente municipal decidiu instalar um parque linear ao longo do Igarapé do Mindu com caráter de corredor ecológico, tendo que promover um trabalho de remoção de muitas famílias que lançavam dejetos domésticos no rio (quadro 1).

Já no estado do Pará, foram traçados calçadões associados a praias fluviais: Orla do Mosqueiro (2003), Orla do Outeiro (2005) e Orla do Icoaraci (2003-2004). Porém os melhores exemplos, no entanto, estão em Belém, cidade da qual durante duas gestões consecutivas foram implantadas diversas propostas paisagísticas ao longo da orla da baía de Guajará, tanto pelo governo estadual quanto pela municipalidade.

Esses projetos foram implementados junto à área central e cujo objetivo foi integrar a cidade com o rio, visto que ela se encontrava isolada das águas por uma barreira de construções. Destaca-se o parque Mangal das Garças, de autoria de Rosa Kliass, possui caráter de parque temático, sendo um parque urbano de forte apelo cenográfico e turístico, com seus viveiros e fontes (quadro 1).

No extremo norte do país, no estado de Roraima, o parque Anauá, em Boa Vista, é considerado o maior parque urbano da região Norte, criado em 1983, concentra diversas atividades culturais, de esporte, lazer, contemplação da natureza e entre outros (quadro 1). Este parque ajuda a conservar as margens do Lago dos Americanos e 


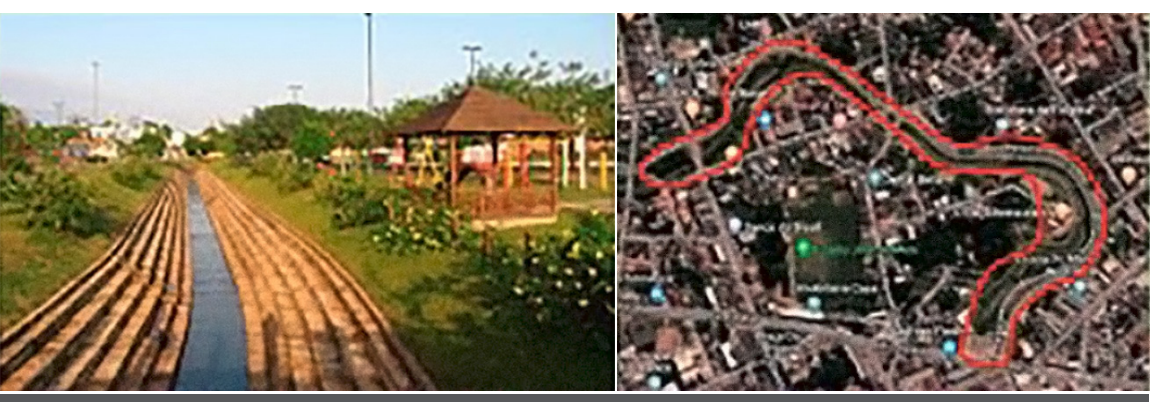

a. Parque da Maternidade - Rio Branco, AC

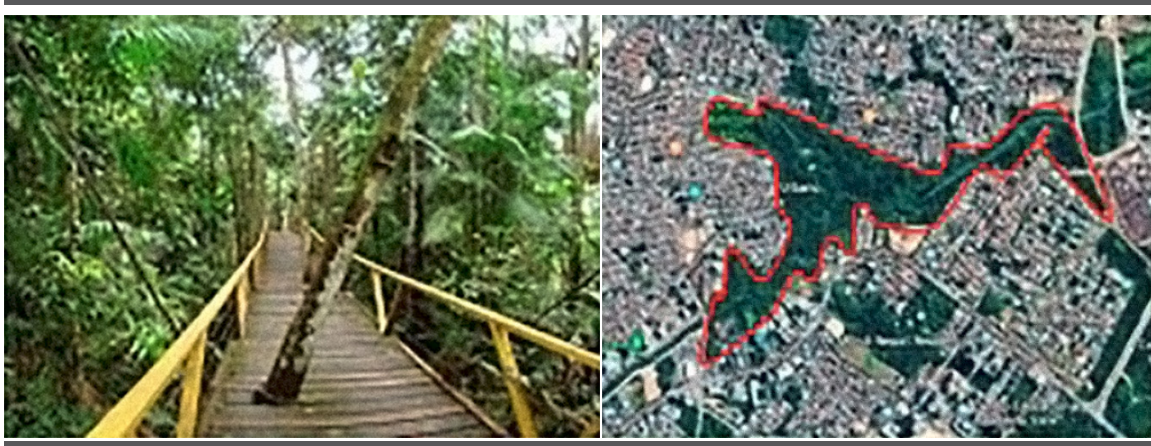

b. Parque do Mindu - Manaus, AM

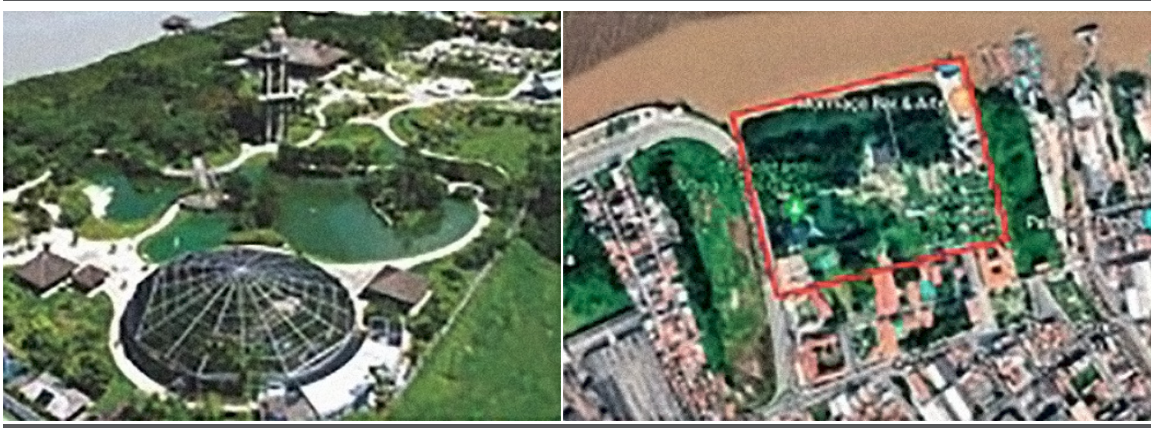

c. Parque Naturalístico Mangal das Garças - Belém, PA

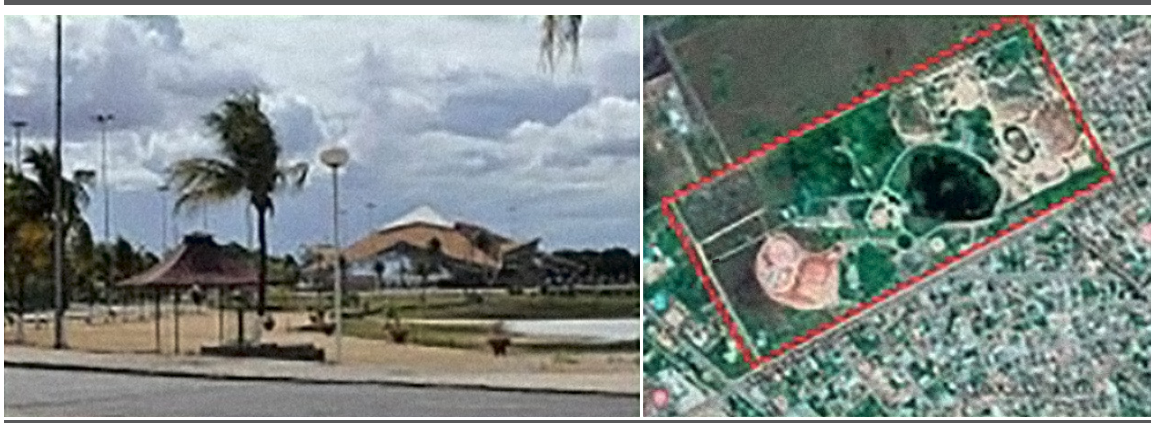

d. Parque Anauá - Boa Vista, RR

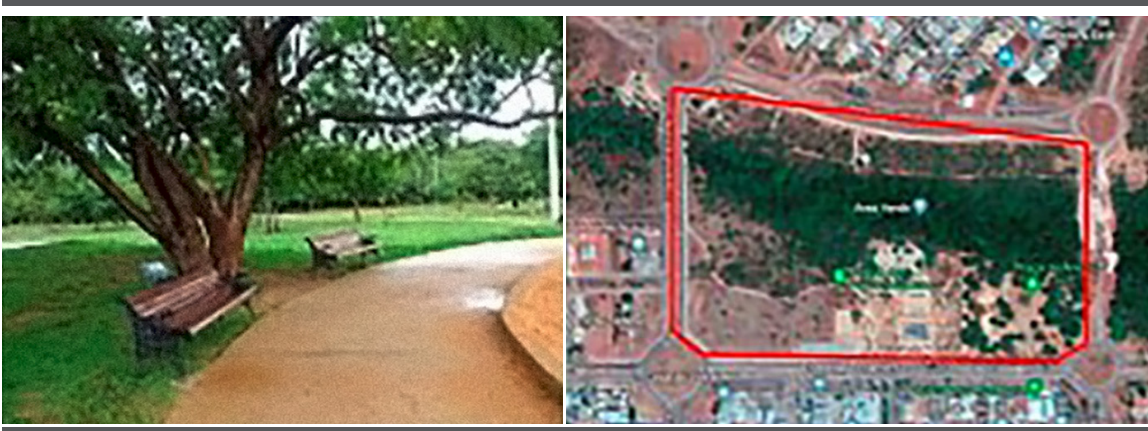

Região Norte do Brasil. Fonte:

Medeiros (2016), Google Earth (2019) e <www.panoramio. com>. Adaptado pelos autores.

d. Parque dos Povos Indígenas - Palmas, TO 
contém resquícios do bioma de savana, também conhecido como "lavrado", sendo de fundamental importância diante das ameaças de expansão urbana e do agronegócio.

O Parque dos Povos Indígenas, na cidade de Palmas, é o primeiro parque linear do estado de Tocantins (quadro 1). Foi inaugurada a primeira de oito etapas do projeto em agosto de 2017, quando concluído, possuirá 17 km de extensão. O local funciona como um corredor ecológico e detém equipamentos de esporte, lazer e educação ambiental, além de valorizar a cultura local das etnias indígenas do Tocantins. Vale ressaltar que foram construídos túneis para passagem de animais para conectar com outros corredores verdes dos futuros parques lineares.

A maioria dos parques apresentados na Região Norte foram implantados a partir dos anos 2000 com objetivos semelhantes em atender demandas de preservação ambiental e de espaços públicos para a população. No entanto, verifica-se que sob um ponto de vista regional, poucas são as políticas públicas que abarcam os projetos de recuperação de rios urbanos de forma abrangente. Existe uma grande dificuldade na implantação das propostas nas prefeituras. Na maioria das vezes, os planos quando são implantados, são efetivados apenas parcialmente, devido à falta de investimentos e à falta de vontade política.

O parque Mangal das Garças, em Belém, tem um modelo de gestão diferente dos demais, pelo fato de ser mantido por iniciativa privada, ter o acesso controlado, além de possuir atrações pagas. A cidade de Macapá, apesar de ser cortada por vários canais urbanos, não possui um parque linear. A cidade é banhada pelo rio Amazonas, possui extensas áreas alagadas, e um grande potencial para implantação de parques lineares nas Áreas de Preservação Permanente de seus córregos e canais.

A criação de uma legislação ambiental no contexto brasileiro, como a criação das Áreas de Preservação Permanente e seu aproveitamento no diagnóstico da Lagoa dos Índios em Macapá, foi inspirada em muitos conceitos apresentados neste tópico. No próximo item será feito uma análise das APPs da região amazônica.

\section{Áreas de Preservação Permanente na Amazônia}

Conforme Medeiros (2016), uma das principais críticas dos ruralistas ao Código Florestal brasileiro é a sua falta de embasamento científico para a definição das metragens das faixas de APPs. Porém, os ambientalistas afirmam que se forem realizados estudos nesse sentido, a metragem mínima a ser protegida para se garantir a preservação da biodiversidade seria muito superior às atuais vigentes na lei. Metzger (2010), por exemplo, alerta para o fato de que apesar de não haver base científica para definir as larguras das APPs, em muitos casos estas deveriam ser muito maiores do que as estipuladas na lei. O pesquisador se questiona se essa largura não deveria variar com a topografia da margem, com o tipo de solo, com o tipo de vegetação, ou com o clima e em particular com a pluviosidade local.

É importante ressaltar que o conhecimento dos processos ecológicos atuantes nas zonas ripárias ainda é muito limitado. Conforme Lima (1996), os estudos das larguras de faixas de proteção ao longo de margens de cursos d'água não são conclusivos. Para esse autor: 
Figura 2: Pressão urbana sobre áreas alagadas em Macapá, AP - Lagoa dos Índios. Fonte: Disponível em <www.panoramio.com>. Acesso em janeiro de 2019.

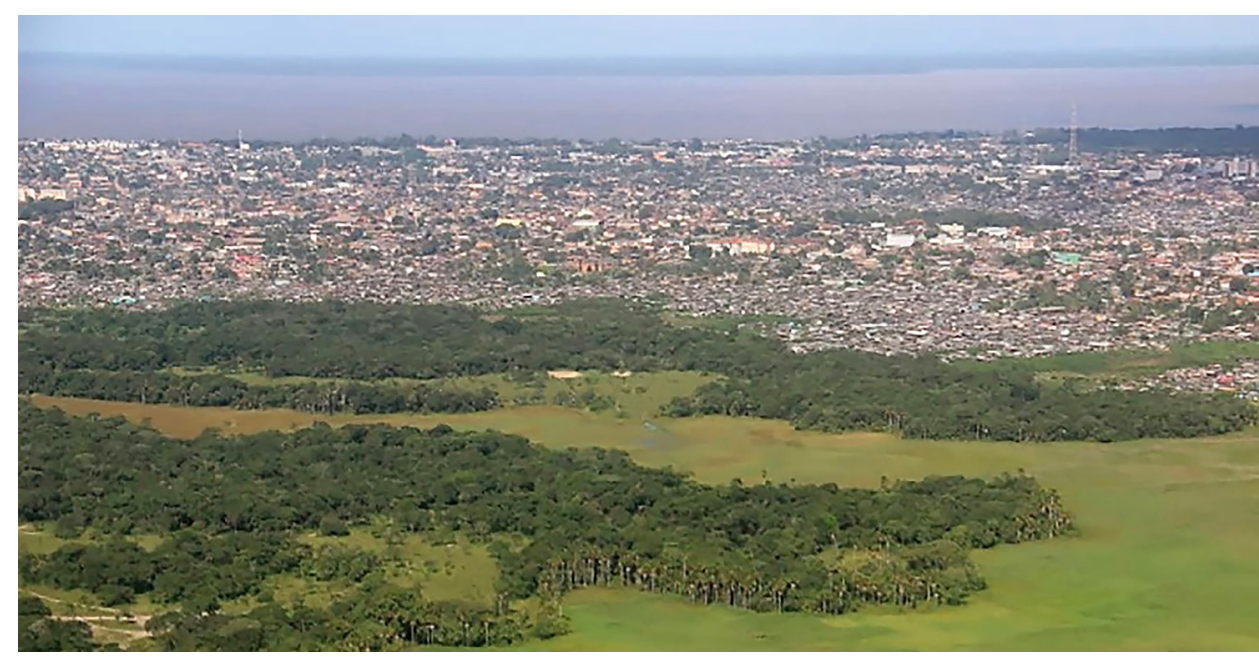

"Os limites da zona ripária, do ponto de vista geomorfológico, não são facilmente delimitados; podem variar bastante ao longo da microbacia e, principalmente, entre diferentes microbacias, em função das diferenças de clima, geologia e solos [...] Não existe ainda nenhum método definitivo para o estabelecimento da largura mínima da faixa ripária que possibilite uma proteção satisfatória do curso d'água". (LIMA, 1996, p.312)

De acordo com o atual Código Florestal (Lei no 12.651/12, art. 4 I) as APPs devem ser demarcadas a partir do leito regular do corpo d'água. Entretanto, esse conceito de regularidade de leito de rios não é aplicável para Amazônia, onde existem variações diárias e sazonais. A amplitude entre os níveis máximo (pico de cheia) e mínimo (vazante) pode variar em até 20 metros.

Na versão anterior do Código Florestal a demarcação era feita a partir do leito mais alto do rio. Essa modificação da Lei, conforme Laurindo e Gaio (2014) representa um grave prejuízo ambiental, pois implica em redução das dimensões das APPs, desrespeitando o princípio da proibição de retrocesso ambiental adotado pela Constituição de 1988. Conforme estes autores:

"A diminuição do referido espaço ambiental protegido não se baseou em estudos técnicos e científicos, o que demonstra a ausência de justificação constitucional para a referida medida, por consequência, não se pode aqui invocar a aplicação dos princípios constitucionais da razoabilidade e proporcionalidade". (LAURINDO e GAIO, 2014, p.08)

Na Amazônia, as várzeas e áreas úmidas desempenham um papel ecológico fundamental no equilíbrio ecossistêmico local, além de proporcionar bens e serviços para o homem. Particularmente no estado do Amapá, é grande o número de áreas de várzea situadas nas zonas urbanas e periurbanas das cidades de Macapá e Santana (Figura 2). Estas áreas vêm sendo ocupadas progressivamente, devido à falta de planejamento urbano e de políticas públicas adequadas para o produtor rural, agravado pelos altos índices migratórios de pessoas oriundas de outros estados da federação brasileira. 
Figura 3: Localização da área de estudo e uso do solo na Lagoa dos Índios. Fonte: Adaptado, (2015).
As áreas úmidas de Macapá e Santana, cidades tipicamente amazônicas, sofrem intensa ocupação urbana, apresentando expressiva deterioração da qualidade ambiental, devido principalmente ao lançamento direto nos corpos d'água de dejetos e efluentes domésticos não tratados. O Igarapé da Fortaleza (principal curso d'água que liga às principais ressacas de Macapá e Santana) e a Lagoa dos Índios possuem um significativo grau de degradação ambiental, onde a retirada das matas ciliares, erosão das margens, assoreamento intensivo e urbanização desordenada, trazem reflexos negativos para a qualidade da água.

Apesar dos assentamentos informais em áreas de APP compreenderem a principal tensão entre as agendas ambiental e urbana, é preciso reconhecer que os pobres não são os únicos atores (MARICATO, 1996). A omissão do poder público e a ganância de proprietários fundiários e imobiliários também são responsáveis pelas ocupações em APPs.

Como afirma Romero (2001) uma consequência da expansão urbana no Brasil tem sido a redução de áreas com vegetação nativa devido às intervenções que desconsideram completamente os elementos naturais da paisagem. A prática da construção concretizase sem considerar os impactos que provocam ao meio ambiente, repercutindo não somente no desequilíbrio do meio, como também no conforto e na salubridade da população urbana.

\section{Diagnóstico da Lagoa dos Índios - Macapá}

O setor costeiro estuarino ou amazônico do Amapá é banhado pelas águas do rio Amazonas e se caracteriza por possuir planícies fluviais inundáveis denominadas localmente como "ressacas". A ressaca da Lagoa dos Índios é um ecossistema rico e biodiverso, drenado por água doce, ligada ao curso principal d'água, o Igarapé da Fortaleza, e influenciada fortemente pela pluviosidade (Figura 3).

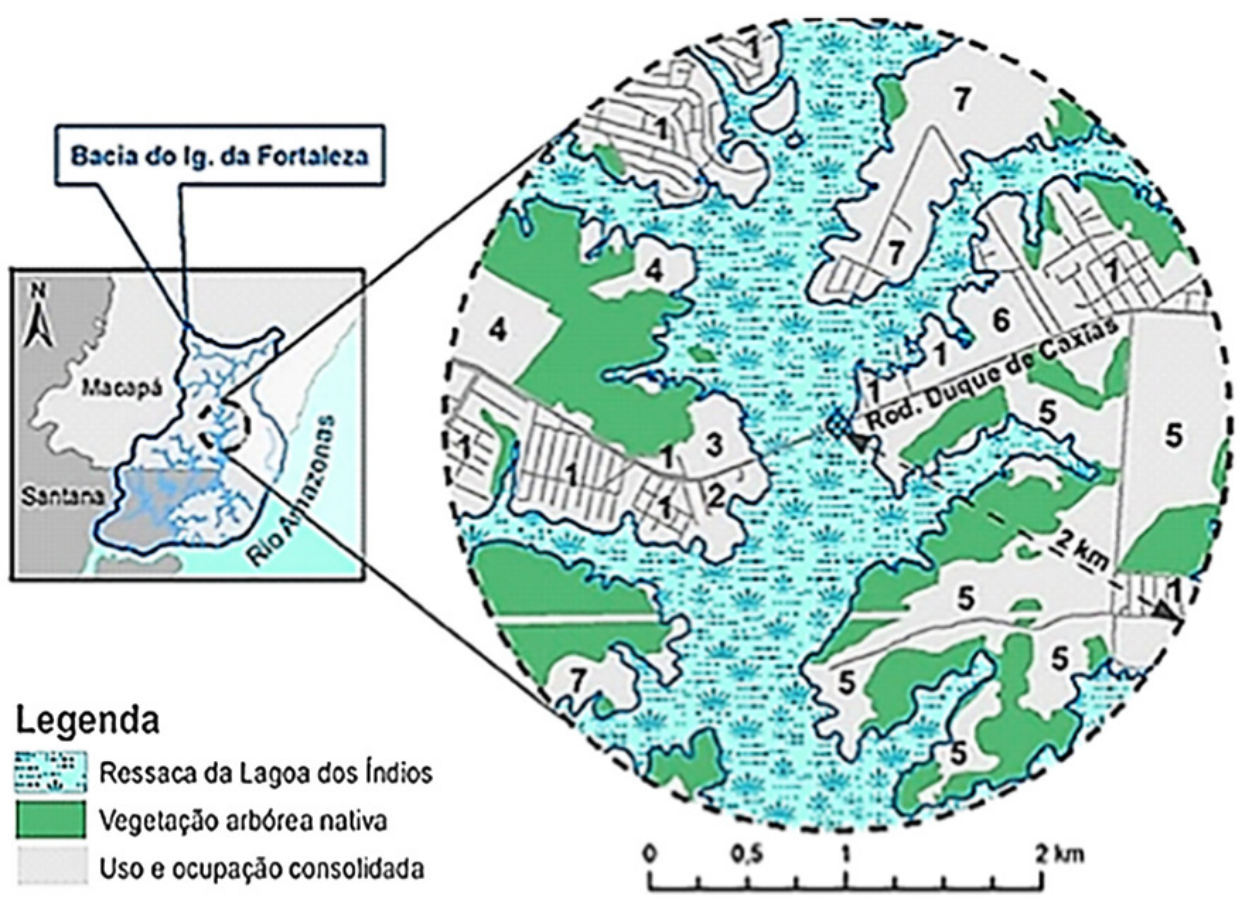


O processo de ocupação das áreas de ressaca na cidade de Macapá teve início por volta da década de 1950. No entanto, é a partir da segunda metade da década de 1980 que este processo de ocupação se intensificou, fazendo com que a alteração na estrutura dessas áreas acontecesse de forma cada vez mais acelerada (PORTILHO, 2010).

Desde 1999 as áreas de ressaca foram tombadas como patrimônio natural (Lei n. 0455/1999 revogada pela Lei $n$. 835/2004) e passaram a ser proibidas instalações de atividades poluidoras, usos do solo que intensificassem processos erosivos e atividades lesivas à biodiversidade. Além do mais, o Plano Diretor de Macapá-AP, Lei Municipal $n^{\circ}$ 029/2004, reconheceu as áreas de ressacas como patrimônio ambiental municipal e determinou várias ações de uso e conservação.

Ao longo do tempo, as intervenções na Lagoa dos Índios passaram de quase imperceptíveis a degradadoras, devido às atividades relacionadas com a expansão urbana desordenada, intensificadas nas décadas de 1980 e 1990 ocasionando diversos conflitos socioambientais (VARGAS e BASTOS, 2013).

Em decorrência dos impactos antrópicos em ressacas de Macapá e Santana, no início da década de 2000 foram realizados os primeiros estudos específicos para a caracterização e diagnóstico dessas áreas (TAKIYAMA, 2004; TAKIYAMA, 2012). Os diagnósticos apontaram que as principais atividades que causam impactos ambientais nessas áreas são: ocupação desordenada do solo, queimadas intencionais, descarte inadequado de resíduos e pastagem para os búfalos. Outras atividades comuns nas áreas de ressaca são: a extração de argila para olarias, a caça e a pesca de subsistência, a piscicultura, a navegação, a extração vegetal e a recreação.

O primeiro instrumento legal de preservação das ressacas foi o Decreto 4297/2002, que delimita o Zoneamento Ecológico Econômico do Estado do Amapá (PZEE-AP). A partir de 2004, quando entra em vigor um novo plano diretor de Macapá, houve diversos avanços na elaboração de legislação voltada para a proteção das áreas verdes. Entre diversas leis criadas, a mais recente é a Lei complementar 030/2004 que prevê projeto de parcelamento para áreas verdes, do qual as ressacas fazem parte.

Percebe-se um grande avanço na elaboração de critérios para ordenar o uso das ressacas e seus instrumentos legais de proteção, entretanto, esses documentos pouco foram efetivados, sendo cada vez mais difícil investir em políticas públicas para remanejar pessoas dessas áreas. A implementação do Decreto (PZEE-AP) é exemplo dessa dificuldade de efetivação, como apresentado por Takiyama et. al:

Em 2009, já com muito atraso, iniciaram-se as atividades de execução do pojeto do ZONEAMENTO ECOLÓGICO-ECONÔMICO URBANO DAS ÁREAS DE RESSACAS DE MACAPÁ E SANTANA, ESTADO DO AMAPÁ pelo IEPA, financiado pelo Ministério Público do Estado do Amapá;(...) Já se passaram vários anos desde o sancionar da Lei Estadual 835/2004 e das Leis que instituem os Planos Diretores de Macapá e Santana e muito pouco se avançou nas ações de proteção das ressacas de Macapá e Santana. (TAKIYAMA ET AL., 2012, p. 81)

Em relação à Lagoa dos Índios, Bastos (2006), destaca que as atividades executadas no entorno desta vêm ocasionando seu assoreamento e alterando a morfologia de drenagens. 


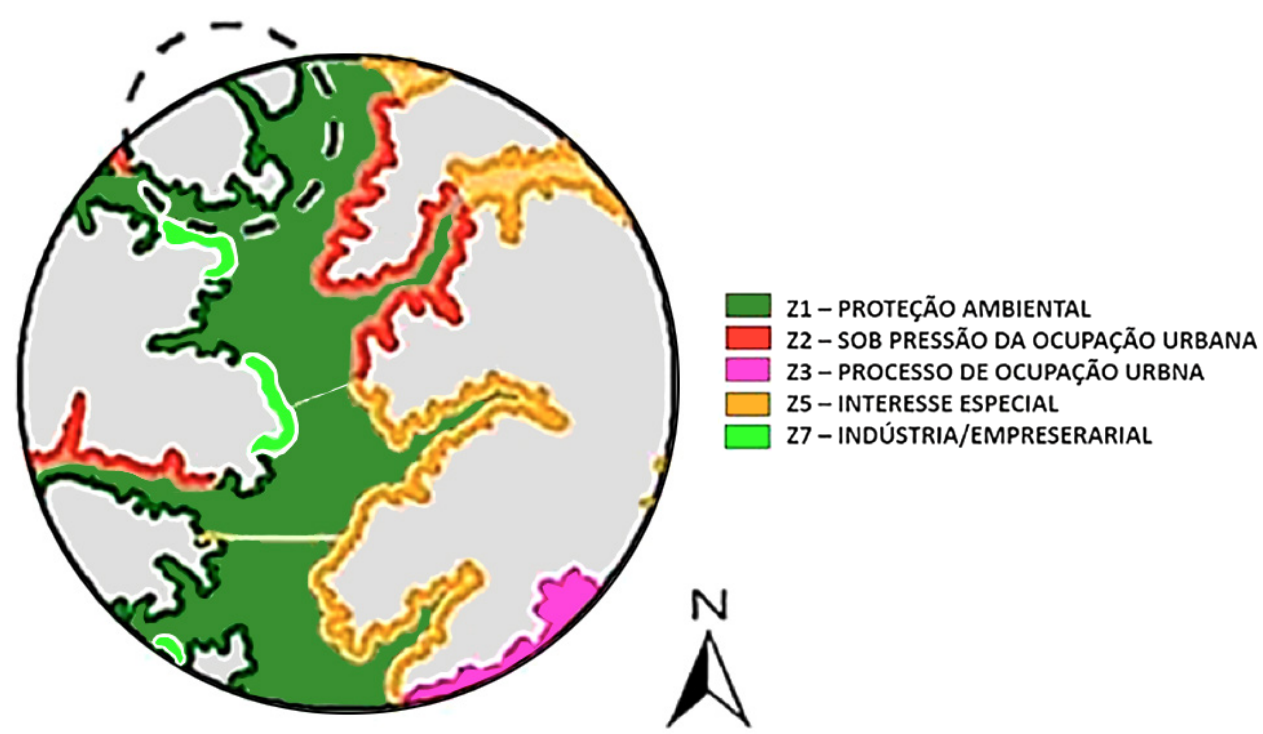

Figura 4: Uso do solo na Lagoa dos Índios. Fonte: Adaptado de Araújo, (2015).
Essa autora verificou o descarte de efluentes líquidos e detritos domésticos produzidos pela presença de atividades de órgãos públicos e das habitações. Essa prática está relacionada à falta de monitoramento e fiscalização pelos órgãos ambientais, mas, sobretudo, pela ausência de infraestrutura urbana do município que não oferece serviços de saneamento básico (BASTOS, 2006).

No entorno da área de ressaca da Lagoa dos Índios observou-se significativas modificações na ocupação do solo. De acordo com a Lei de Uso e Ocupação do Solo do Município de Macapá (Lei n 029/2004) essa área era prevista como Setor Residencial. Em 2009, essa área não possuía edificações, mas ao longo do tempo passou a ser ocupada em decorrência da expansão urbana, que ocorreu de forma horizontal e desordenada. As análises da imagem de satélite demonstram que a região passou por um processo de desmatamento da vegetação nativa dando lugar ao bairro conhecido popularmente como "Marabaixo IV", uma expansão do bairro Marabaixo (figura 4).

Percebe-se na figura 4, na zona tracejada, a ocupação do bairro Marabaixo IV que se formou nos últimos anos. O fator da maior facilidade de acesso à zona leste pela rodovia Duca Serra induziu a expansão e ocupação sem o planejamento na área da Lagoa dos Índios, e que ainda não há uma atualização do plano diretor, defasado desde 2014, e nem um plano de manejo para essa zona.

Através de visitas de campo foi percebido que os habitantes do bairro Marabaixo IV são em sua maioria de baixa renda. A infraestrutura do local é precária, contando apenas com uma iluminação pública nos principais acessos. Não existe rede de água encanada e de coleta de esgoto, a pavimentação é recente e está nas vias principais. Em relação ao abastecimento de água observou-se que a população perfura poços sem projetos ou licenciamento. Há ainda alguns loteamentos e casas de renda média-alta que invadem a área de ressaca com infraestruturas para lazer e atividades agrícolas. 
Figura 5: Imagem aérea da Rodovia Duca Serra na Lagoa dos índios. Fonte: GoogleEarth, 2019.
Deste modo, os principais problemas ambientais encontrados na área em estudo da Lagoa dos Índios são gerados pela ocupação desordenada tanto de classe baixa quanto alta e pelo aterramento da duplicação da rodovia Duca Serra, que contribui tanto para o aumento de fluxo de veículos, quanto para a expansão urbana em seu entorno. No item a seguir serão apresentados os resultados obtidos, referentes ao entendimento dos conflitos atuais que impedem a implantação de um parque linear nas margens da lagoa.

\section{Resultados obtidos}

A ressaca da Lagoa dos Índios funciona como uma bacia de acumulação de águas pluviais e sofre influência da bacia do Igarapé da Fortaleza. A Lagoa dos índios é a maior área de ressaca de Macapá, com aproximadamente 8.892 Km² é conectada a outras ressacas e sua extensão passa por vários bairros de Macapá e Santana (figura 5).

Ao longo dos anos o fluxo de veículos ficou intenso na rodovia Duca Serra em consequência da expansão urbana para a zona leste, com a presença de vários condomínios residenciais e de empresas. O governo do estado do Amapá tomou a medida de duplicar a rodovia para facilitar o escoamento em 2017, o que aterrou parte da área alagada.

O Ministério Público do Estado do Amapá entrou com um recurso para a geração de um TAC - Termo de Ajustamento de Conduta n 025/2017 MP/PRODEMAC para amenizar os efeitos do aterramento (figura 6), em que o documento exige a implantação de um parque urbano ao longo das margens da Lagoa dos índios.

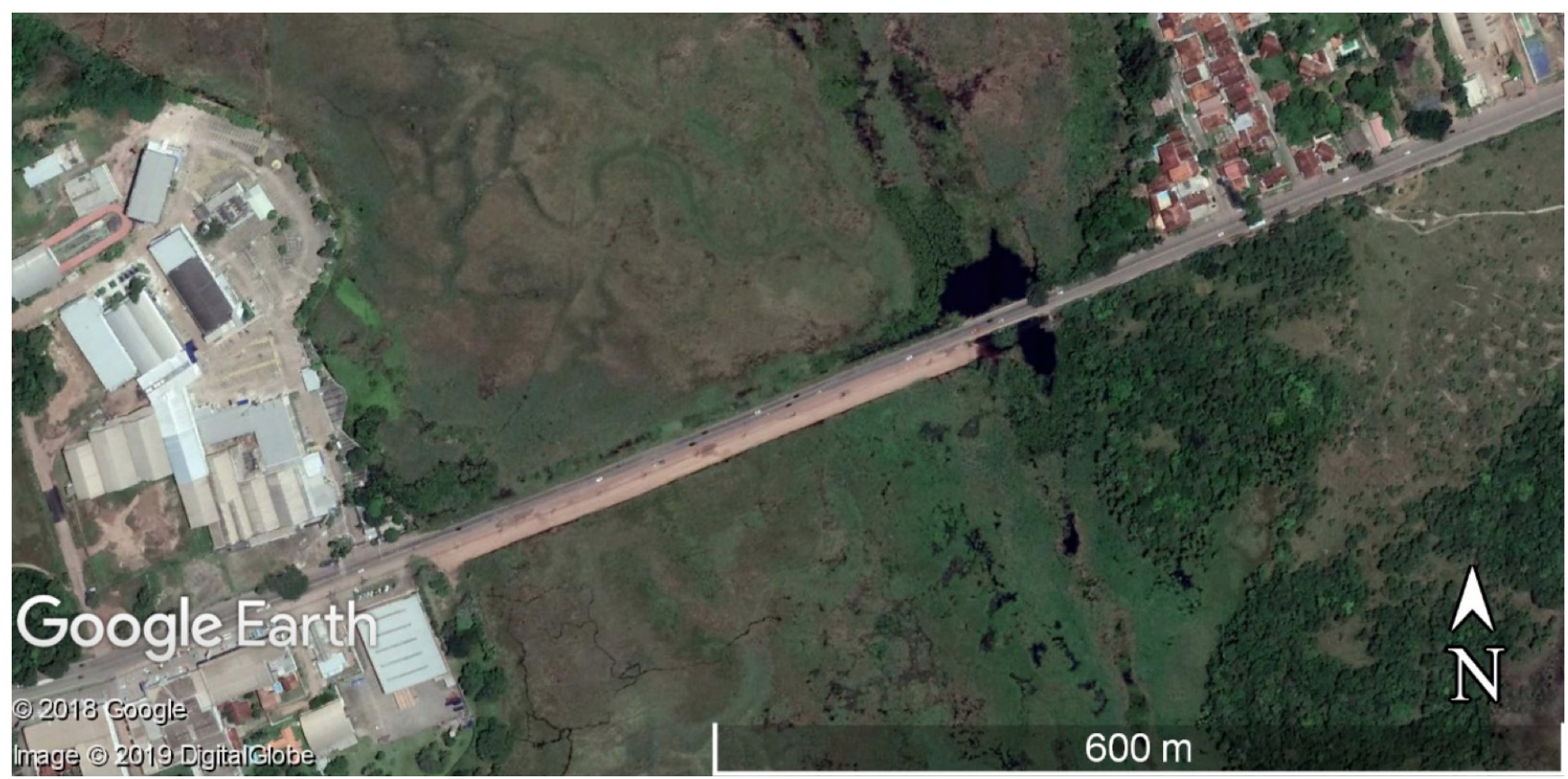


Figura 6: Obra da duplicação da ponte na rodovia Duca Serra. Fonte: Foto dos autores, 2019.

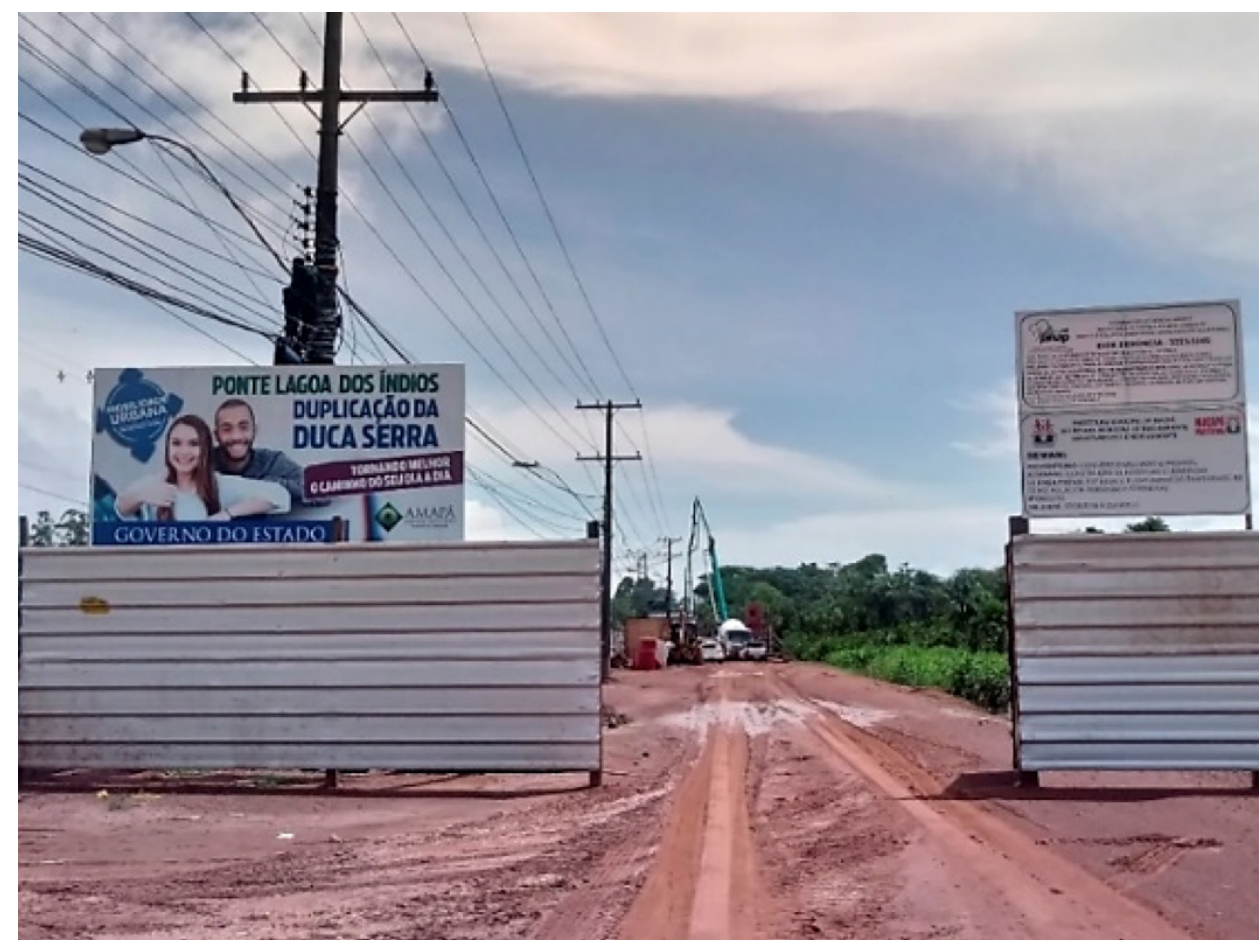

Segundo o Ministério Público do Estado do Amapá, este será o maior parque urbano da região Norte, porém não houve até o momento a delimitação exata de seu perímetro. Estudos para a implantação estão sendo realizados pela Secretaria de Meio Ambiente do estado, que deveria entregar um relatório técnico em janeiro de 2018, porém pediu mais tempo para elaborar tal documento.

Foi realizada uma consulta pública sobre o TAC no dia 16 de março de 2018 na quadra poliesportiva da Faculdade de Macapá (FAMA), a reunião estava marcada para nove horas e iniciou apenas dez e meia da manhã, sendo que houve falas de diversos parlamentares por longos períodos até ser falado sobre a proposta próximo de meio dia, momento em que muitas pessoas já haviam ido embora.

A intenção inicial do TAC era de implantar um grande parque urbano, porém, pode ter ocorrido uma falta entendimento sobre o que representa um parque, ora confundido com reserva ambiental, praça, e entre outros. A definição dos parques urbanos do Brasil é pouco precisa na atualidade, muitos parques de pequeno porte possuem características de praças de vizinhança (MACEDO, 2010). O mesmo autor afirma que parque urbano é:

Todo espaço de uso público destinado à recreação de massa, qualquer que seja seu tipo, capaz de incorporar intenções de conservação e cuja estrutura morfológica é auto-suficiente, isto é, não é diretamente influenciada em sua configuração por nenhuma estrutura construída em seu entorno. (MACEDO, 2010, p.14) 
Os autores estiveram na consulta pública e perguntaram se havia intenção de implantação de um parque urbano como resultado do TAC, entretanto foi respondido pela Secretaria de Meio Ambiente - SEMA que não, pois a proposta é de demarcação apenas de novas áreas de proteção, em que uma delas está na ressaca da Lagoa dos Índios.

A proposta foi apresentada pela SEMA para a criação da Área de Proteção Ambiental - APA da Lagoa dos Índios, APA Igarapé da Fortaleza e Área de Relevante Interesse Ecológico - ARIE Tacacá. A consulta pública teve caráter de sugestões para alterações nas áreas definidas como APAs, a delimitação dessas áreas estava prevista para agosto de 2018, de acordo com o secretário da SEMA na época, conhecido como Bernardinho, entretanto até 2019 isso ainda não ocorreu.

O levantamento da SEMA foi secundário e foram realizadas algumas visitas de campo nas futuras áreas de proteção. Vale ressaltar que não foi explicada na consulta pública a real origem do TAC, o aterramento ocasionado pela duplicação da rodovia Duca Serra e nem quem é o responsável, o Governo do estado.

Foi elaborado um relatório técnico (SEMA, 2017) sobre o TAC, o documento apresenta um diagnóstico das áreas a serem protegidas baseado em bibliografias e visitas de campo para uma caracterização do meio biológico, físico, potencial para visitação pública, socioeconômico e da situação fundiária.

Neste diagnóstico foram apontados os seguintes problemas ambientais nas áreas de ressaca analisadas: Desequilíbrio ecológico nas ressacas; Risco de proliferação de doenças; Acúmulo de lixo doméstico; Risco de afogamento em épocas de fortes chuvas; Carência de infra-estrutura; Risco de incêndio, principalmente nos períodos de estiagem (SEMA, 2017, p.18). Dessa forma, é necessária a implantação de infraestrutura e de planos de manejo para cada unidade ter sua conservação garantida (SEMA, 2017).

Apesar disso, é feita uma crítica sobre o desinteresse dos próprios órgãos públicos em realizar a gestão das ressacas "Verificou-se a falta de interesse dos órgãos públicos, para a grande problemática ambiental que atingem as áreas de ressacas localizadas no centro urbano da cidade de Macapá" [...] (SEMA, 2017, p.19).

Foi publicado no website do governo (Amapá, 2019) que a obra total da duplicação da Duca Serra está prevista para ser entregue no final de 2019, e a obra na área em estudo esteve parada desde 2018, apenas com o aterro, e agora está sendo construída uma ponte de duplicação orçada em 7,7 milhões prevista para entrega em agosto de 2019 (figura 7).

Ainda sobre a mesma notícia, o orçamento para a obra da duplicação da ponte na rodovia também contempla outros elementos apontados:

"De acordo com a Setrap, a estrutura foi planejada para suportar a movimentação da água, mesmo em períodos em que a maré atinge níveis máximos de enchente, principalmente, no inverno. O projeto também prevê a revitalização de todo o entorno da Lagoa dos Índios, que mede 420 metros, onde serão construídas quatro pistas, ciclovia, área de contemplação, acostamento, sinalização e iluminação". (AMAPÁ, 2019) 
Figura 7: Placa de obra da ponte na rodovia Duca Serra. Fonte: Amapá (Estado), 2019.

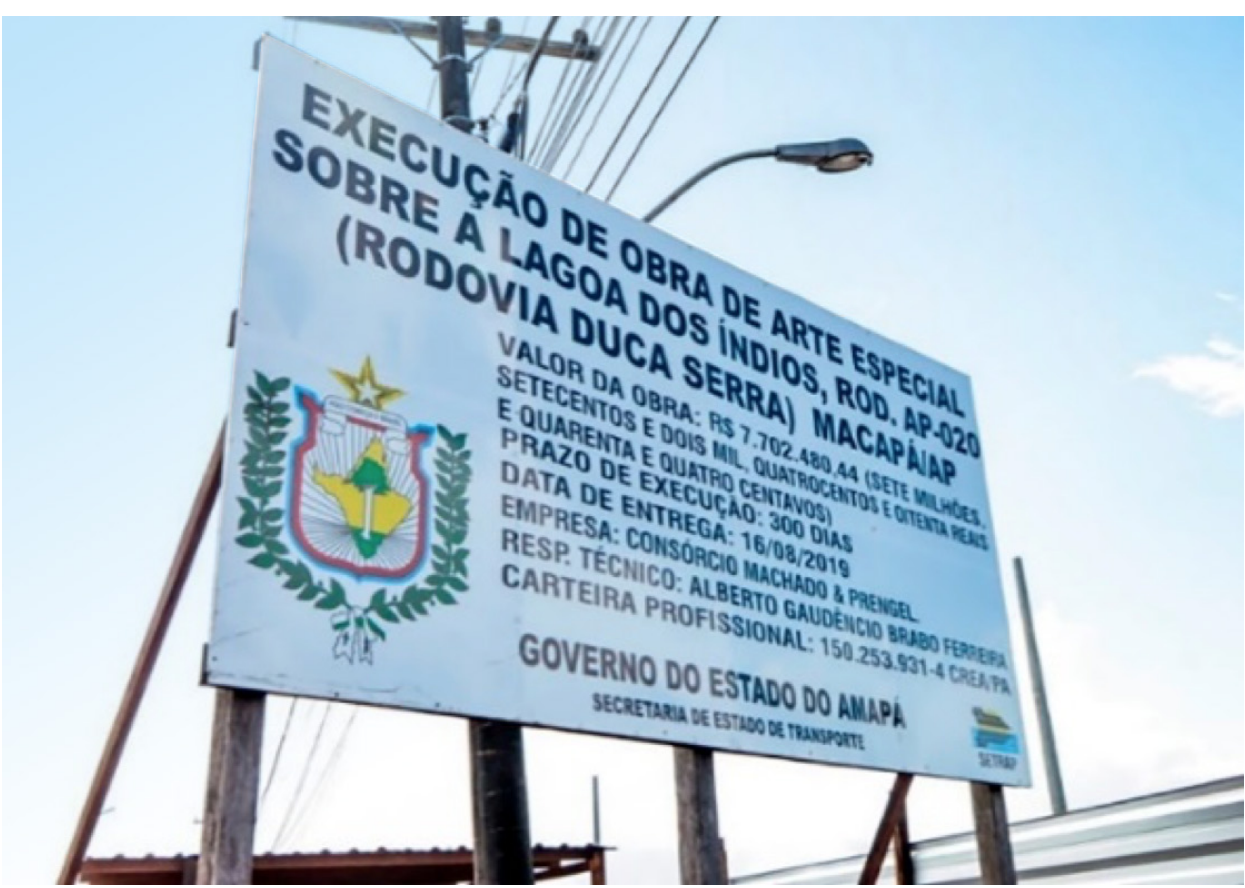

Portanto, percebe-se que esta obra da ponte promete além de mais pistas de rolamento, maior acessibilidade para ciclistas e pedestres, o que é uma infraestrutura básica que tem sido implementada recentemente. O valor da infraestrutura da duplicação da rodovia Duca Serra nesse trecho da Lagoa dos Índios é suficiente para implantar um parque urbano na área, mas a prioridade do Governo, a pressão de empresas e da população em geral está voltada à essa duplicação.

Em relação ao potencial da visitação, o relatório afirma que transformar as ressacas em UC's não deve afastar e sim integrar o homem à natureza e mostra a importância de implantar estruturas de visitação de baixo impacto para o turismo ecológico. É admitido que há carência de espaços públicos de lazer que integrem com a natureza e que "Pensar em estruturas com espaços de usos contínuos para esse público viabiliza a efetivação dessas UC's permitindo que se alcance seus objetivos de criação" (SEMA, 2017, p.21).

Para elaboração de um projeto arquitetônico de um parque urbano na Lagoa dos Índios deve-se perceber as características levantadas no diagnóstico realizado por este e os estudos anteriores, considerando os aspectos descritos sobre planejamento ambiental de parques lineares. $O$ projeto de um futuro parque linear às margens da ressaca da Lagoa dos Índios precisa ter um projeto paisagístico inovador e contemporâneo, mas sem desvincular-se das características locais que inspirarão a concepção de ideias. 
Um parque nas margens de uma grande lagoa precisa permitir o convívio da população, desenvolvimento da educação ambiental e de expressões culturais. Deverá ser destinado à um público amplo e variado, desde a população de bairros adjacentes aos mais afastados, incluindo turistas de outros estados. Para o reordenamento espacial da área, seria importante a remoção das ocupações às margens da ressaca, que não respeitam afastamentos e usos compatíveis aos descritos pelas legislações ambientais.

\section{Considerações finais}

As áreas de preservação permanente são ecossistemas biodiversos e frágeis em termos de susceptibilidade a impactos antrópicos, e estes têm se intensificado nas últimas décadas por falta de um planejamento urbano adequado.

Na região Amazônica, a enorme quantidade de cursos d'água e áreas de várzea, somados ao modo de vida ribeirinho e a falta de suporte habitacional das capitais, tornam inevitáveis as ocupações humanas em Áreas de Proteção Permanente. No Município de Macapá, o estudo de caso da Lagoa dos Índios exemplifica os conflitos socioambientais que ocorrem por toda Amazônia, desrespeitando as legislações ambientais e urbanas. Verificou-se escassez de estudos que abordam a quantificação da degradação ambiental e diagnóstico da situação atual das áreas protegidas nessa região.

Há diversos problemas para a implantações de parques em Macapá como a falta de priorização de políticas públicas e recursos para tal, a gestão descontinuada a cada novo mandato, além da ausência de um planejamento urbano. Ocorre a falta de incentivos e fiscalização para usos sustentáveis das áreas de ressaca e tampouco há mobilização social organizada para contestar as medidas do governo em propor obras de infraestrutura que degradem a área de ressaca da Lagoa dos Índios.

Os recursos destinados à implantação de infraestrutura da duplicação da rodovia Duca Serra não contemplaram a efetiva implantação de um parque urbano nas margens da Lagoa dos Índios. Não existe a previsão para a construção de equipamentos de esporte, lazer, recuperação do solo, vegetação, enfim, toda a infraestrutura paisagística necessária. Percebe-se que a administração pública tem priorizado apenas a mobilidade automotora, visando a interesses de grupos específicos, pois sabe-se que quanto mais se investe em alargamento de vias, mais se induz a compra de veículos e congestionamentos.

É urgente a criação de novos parques lineares na região Norte devido a abundância de cursos d'água ainda recuperáveis, a carência de espaços de convivência e com problemas de drenagem urbana, em uma região de clima quente e úmido, com altos índices pluviométricos.

A ressaca da Lagoa dos índios sofre ameaça de degradação pelas moradias em seu entorno e pelo grande fluxo de veículos pela rodovia Duca Serra. As medidas estão sendo tomadas lentamente pelo poder público, mas para que haja a recuperação do bioma é necessário um projeto paisagístico que contenha rapidamente essas ameaças e esteja adequado às características socioambientais amazônicas. 


\section{Referências bibliográficas}

AMAPÁ (Estado). Lei n. 0835, de 27 de maio de 2004. Dispõe sobre a ocupação urbana e periurbana, reordenamento territorial, uso econômico e gestão ambiental das áreas de ressaca e várzea localizadas no estado do Amapá e dá outras providências.

AMAPÁ (Estado). Website do Governo do Amapá. Governo inicia construção da nova ponte na Lagoa dos Índios. Disponível em: <https://www.portal.ap.gov.br/ler_noticia.php?slug=2301/ governo-inicia-construcao-da-nova-ponte-na-lagoa-dos-indios>, acessado em 02/04/2019.

AHERN, Jack. Greenways as a planning strategy. Landscape and Urban Planning. Volume 33, Issues 1-3, Greenways, October 1995, p.131-155.

ARAÚJO, Dayanne Dos Santos. Diagnóstico Ambiental Da Lagoa Dos Índios, Macapá-Ap, Brasil. Monografia, UEAP. MACAPÁ, 2015.

BASTOS, Cecília Maria B. Conflitos ambientais urbanos em áreas de ressaca: Um estudo da comunidade Negra da Lagoa dos Índios em Macapá/AP. Dissertação de Mestrado. Universidade de Brasília - UNB. 2006.

BROCANELI, Pérola. O ressurgimento das águas na paisagem paulistana: fator fundamental para a cidade sustentável. Tese (Doutorado). Faculdade de Arquitetura e Urbanismo, Universidade de São Paulo, 2007.

BRASIL. Lei $n^{\circ}$ 12.651, de 25 de maio de 2012. Código Florestal brasileiro - dispõe sobre a proteção da vegetação nativa.

BRASIL. Decreto n. 4297, de 10 de julho de 2002. Regulamenta o art. 9o, inciso II, da Lei no 6.938, de 31 de agosto de 1981, estabelecendo critérios para o Zoneamento EcológicoEconômico do Brasil - ZEE, e dá outras providências.

FÁBOS, Julius. Introduction and overview: the greenway movement, uses and potentials of greenways. Landscape and Urban Plannig. Volume 33, Issues 1-3, Greenways, October, 1995.

FÁBOS, Julius. Greenway planning in the United States: its origins and recent case studies. Landscape and Urban Planning, Volume 68, p. 321-342, 2004.

FORMAN, R.T. Corridors in a landscape: Their ecological structure and function. Ekologiya 2, 375-385. 1983.

FORMAN, R. T. Land Mosaics: The Ecology of Landscapes and Regions. Cambridge/New York: Cambridge University Press, 1995.

FORMAN, R. T.; GODRON, M. Landscape ecology. New York: John Wiley \& Sons, 1986.

FLINK, C. A.; SEARNS, R. M. Greenways: A Guide to Planning, Design and Development. Washington, DC: Island Press. 1993. 351p.

GIORDANO, Lucília. O conceito de corredores verdes (greenways) no planejamento para prevenção de inundações. Artigo. I Fórum de Debates sobre Ecologia Da Paisagem e Planejamento Ambiental: Riscos Ambientais nos Trópicos Úmidos: Movimentos de Massa e Inundações. Rio Claro: UNESP, 04 a 08 de Junho de 2000.

GIORDANO, Lucília; RIEDEL, Paulina. Técnicas de SIG e sensoriamento remoto no planejamento ambiental de parques lineares. Revista Brasileira de Cartografia No 58/02. Agosto, 2006.

LAURINDO, V.; GAIO, D. As Áreas de Preservação Permanente do Novo Código Florestal e o Princípio da Proibição de Retrocesso Ambiental. In: $3^{\circ}$ Seminário Nacional sobre o Tratamento de Áreas de Preservação Permanente em Meio Urbano e Restrições Ambientais ao Parcelamento do Solo, Belém, 2014.

LIMA, Catharina Pinheiro. A natureza na cidade, a natureza da cidade. São Paulo, Tese (doutorado em Arquitetura e Urbanismo) - FAUUSP, 1996. 
MACAPÁ, Prefeitura Municipal de. Plano Diretor de Desenvolvimento Urbano e Ambiental de Macapá. Macapá. 2004.

Lei complementar no 029, de 24 de junho de 2004. Institui as normas de uso e ocupação do solo no município de Macapá e dá outras providências.

Lei complementar $n^{\circ}$ 030, de 24 de junho de 2004. Dispõe sobre o parcelamento do solo urbano do município de Macapá e dá outras providências.

MACEDO, Silvio Soares; SAKATA, Francine Gramacho. Parques urbanos no Brasil. São Paulo, Edusp, 2010.

MACEDO, Silvio Soares. Paisagismo Brasileiro na Virada do Século: 1990-2010. São Paulo: Editora de São Paulo; Campinas; Editora Unicamp, 2012.

MCHARG, Ian. Design with Nature. New York: John Wiley \& Sons, 1969.

M'IKIUGU, Martin; KINOSHITA, Isami; TASHIRO, Yoritaka. Urban Green Space Analysis and Identification of its Potential Expansion Areas. Artigo. In Procedia - Social and Behavioral Sciences 35, 2012, p.449- 458.

MARICATO, E. Metrópole na periferia do capitalismo: ilegalidade desigualdade e violência. São Paulo: Hucitec, 1996.

MEDEIROS, José Marcelo. Parques Lineares ao longo de corpos hídricos urbanos: Conflitos e possibilidades; O caso da Orla do Lago Paranoá. Tese de Doutorado. Universidade de Brasília, Faculdade de Arquitetura e Urbanismo, 2016.

METZGER, Jean Paul. O Código Florestal tem base científica? Artigo. In: Natureza \& Conservação, 8(1):1-5, 2010.

PORTILHO, Ivone dos Santos. Áreas de Ressaca e Dinâmica Urbana em Macapá/AP. Artigo.In: VI Seminário Latino-Americano de Geografia Física II Seminário Ibero-Americano de Geografia Física Universidade de Coimbra, Maio de 2010.

ROMERO, Marta A. B. A arquitetura bioclimática do espaço público. Brasília: Editora Universidade de Brasília, 2001.

SEARNS, Robert M. The evolution of greenways as an adaptative urban landscape form. Landscape and Urban Planning. Volume 33, Issues 1-3, Greenways, p.65-80. October 1995.

SEMA. Relatório Técnico n 1/2017: Comissão de estudos de Criação de Unidades de conservação das Ressacas - Portaria n 126/2017. Macapá, 2017.

STEINITZ, C., PARKER, P., JORDAN, L. Hand drawn overlays: Their history and prospective uses. Landscape Architecture 9, 1976, p. 444-455.

SMITH, D. S.; HELLMUND, P. L. Ecology of Greenways. Minneapolis, MN: University of Minnesota Press. 1993. 222p.

TAKIYAMA, L.; SILVA, Q ; COSTA, P.; NASCIMENTO, S. Qualidade das águas de ressaca Bacias do Igarapé da Fortaleza e Rio Curiaú. In:TAKIYAMA, L.R.; SILVA, A.Q. da (Orgs.). Diagnóstico das Ressacas do Estado do Amapá: Bacias do Igarapé da Fortaleza e Rio Curiaú, MacapáAP, CPAq/IEPA e DGEO/SEMA, 2004.

TAKIYAMA, L.; SILVA, L.; JIMENEZ, A.; PEREIRA, A.; ZACARDI, M.; FERNANDES, F.; SOUTO, F; SILVA, A.; SILVA, M.; SANTOS, C.; NETO, C.; SANTOS, C. Zoneamento Ecológico Econômico Urbano das Áreas de Ressacas de Macapá e Santana, Estado do Amapá. Relatório Técnico. Macapá, 2012.

VARGAS, M.; BASTOS. B. Conflitos ambientais urbanos e processos de urbanização na Ressaca Lagoa dos Índios em Macapá/AP. Cad. Metrop., São Paulo, v. 15, n. 29, pp. 265-288, jan/jun 2013. 